\title{
Big Five Factors and academic achievement in Russian students
}

\author{
Irina A. Novikova*, Alexandra A. Vorobyeva \\ Peoples' Friendship University of Russia \\ *Corresponding author. E-mail: novikova_ia@rudn.university
}

Background: The Five-Factor Model (FFM) of personality traits is one of the most comprehensive personality models in modern psychology. The traits, or domains, of the model, provide an extensive framework, which allows researchers to analyse the correlation between the aspects of personality and various aspects of social behaviour. Academic achievement is a key factor in a subject's success, and a more comprehensive understanding of its potential factors could improve educational programs and teaching strategies.

Objectives: The purpose of this paper is to consider the correlations between the FFM (Big Five) personality traits and the academic achievement of university students in various fields of study.

Design: This study has adopted a descriptive analytic approach by exploring previous research data. In the present empirical research, the Big Five factors were measured with the Russian NEO Five-Factor Inventory adaptation by S. Biryukov and M. Bodunov. Academic achievement was defined as the average value of the semester final grades. The Spearman correlation analysis was used for statistical analysis. The sample includes 207 first- and second-year university students in the Linguistics Department.

Results: The analysis of the published data revealed that Western psychological studies show that consciousness and openness, two values in the model, are more closely connected with the peculiarities of the students' academic achievement in different fields of study, but similar studies conducted in Russian universities do not fully confirm this data. Findings of our research proved that consciousness is more associated with greater academic achievement of Russian linguistics students in most fields of study compared to the other FFM traits, while other traits showed more specific correlations with particular fields of study.

Conclusions: The data suggests that both environmental and internal psychological factors, such as motivation, intelligence, inclinations, abilities, etc. affect academic achievement. However, further research suggests that volitional and cognitive personality traits considered in the framework of various models of personality may have a great influence on academic achievement and should also be taken into consideration. Personality traits, especially consciousness and openness of the FFM, are significant factors of academic achievement. The associations between academic achievement and FFM traits are more prominent in those fields of study that include such features as their relative 
novelty, difficulty or interest for students (Second Foreign Language, Special Disciplines, and Psychology \& Pedagogics).

Keywords: Five-Factor Model (FFM), academic achievement, personality traits, linguistics students; Russian NEO Five-Factor Inventory

\section{Introduction}

Presently, education may be regarded as an ongoing process that continues throughout one's life. Thus, research into the most important factors associated with academic achievement is one of the key issues to be resolved in psychology.

Modern psychology provides various points of view on this issue, and researchers distinguish different groups of academic achievement predictors (Kappe \& Van der Flier, 2012; Gordeeva, 2011; Gordeeva, 2012; Azhar, Nadeem, Naz, Perveen, \& Sameen, 2014; Vasileva-Stojanovska, Malinovski, Vasileva, Jovevski, \& Trajkovik, 2015; Dhandabani \& Sukumaran, 2015; Yushau \& Omar, 2015). These factors can be divided into several groups:

1) individual features of the students, such as specific abilities, talents, temperament, sex, age, health status, etc.;

2) cognitive ability features, mainly one's intellect, level of intellectual development and creativity;

3) learning motives and motivation features;

4) learning styles or learning strategies;

5) personal traits or dispositions;

6) various environmental factors, for example, special features of the educational process organisation, culture differences, economic conditions, family conditions, the form of study, etc.

Cross-cultural studies of the factors associated with academic achievement are becoming even more relevant due to the globalisation processes that affect education (among other areas). These studies help to define the influence of different variables, such as personality traits, in different national and cultural samples. We believe that this research direction is highly relevant in the context of the Bologna Process and the formation of the European Higher Education Area (EHEA) and the significantly increased academic mobility of the students.

The purpose of this paper is to consider the Big Five personality traits as the factors of academic achievement in university students across different cultures, as we believe that will be beneficial for higher education teachers working in a new educational environment and dealing with a new brand of international students.

\section{Five-Factor Model of personality (Big Five model) across cultures}

Presently, the most common version of the Five-Factor Model (FFM) or the big five model is the one developed by P. Costa and R. McCrae (1992), which is based on a number of previous studies (Tupes \& Christal, 1961; Goldberg, 1992; Digman, 1997). The FFM framework states that the factors (also referred to as 'traits' or 'domains') are orthogonal and each of them comprises six facets. The FFM includes such factors as neuroticism, extraversion, openness to experience, agreeableness 
and conscientiousness, which are described in the literature (McCrae \& John, 1992; McCrae \& Costa, 2004; Furnham, Heaven \& 1999; Novikova, 2013; Thompson, 2008; Vorobyeva, 2011).

Cross-cultural studies of the FFM using adapted personality inventories show that the five-factor structure is consistently reproduced in various national samples, although some studies tend to point out insignificant differences in descriptions of certain domains. The original five-factor structure was found in Dutch, Italian, German, Australian, Israeli, Korean, Japanese and other national samples, which suggests that the five-factor structure may be considered as a basic structure of human personality (McCrae, 2002). However, a number of studies show that this structure does not always reproduce, for example, in some cases, a smaller number of factors is obtained, e.g., for the Hungarian sample agreeableness is not reproduced (Szirmak \& De Raad, 1994), and there are significant difficulties with the reproduction of openness in Asian samples. Sometimes, more than five factors are obtained in certain samples (Gurven et al. 2013; Katigbak et al., 2002; Lodhi, Deo, \& Belhekar, 2002; Matsumoto \& Juang, 2008; Thalmayer \& Saucier, 2014; Funder, 2010; Trull \& Geary, 1997).

The FFM framework is widely used across many countries to study relations between personal traits and various aspects of social behavior, including Hofstede's cultural dimensions, one's attitude towards health, learning process, profession, computer gaming, etc. (Furnham \& Heaven, 1999; Novikova, 2013; Ostendorf, 1990; Fazeli, 2012; Yushau \& Omar, 2015).

A number of studies in the Big Five framework were conducted in Russian psychology. The main issues addressed in those studies are the validation of the FFM for the Russian sample, the research of the internal structure of the model (various research data suggests a non-orthogonality of the domains and existence of broader meta-factors), the cross-cultural studies and the research of associations between the Big Five model traits with various aspects of activity, including academic achievement.

Studies concerning the adaptation and validation of the FFM on the Russian sample to create adequate diagnostic tools have been conducted since the 1990s (Bodunov \& Biryukov, 1989; Khromov, 2000; Oryol \& Senin, 2004; Knyazev, Mitrofanova, \& Bocharov, 2010). Cross-cultural and twin studies in the FFM framework should also be mentioned; the results of these studies are consistent with those obtained in other national samples for extraversion and openness (Nizamova, Ptukha, \& Lobaskova, 2013).

However, it should be noted that most Russian studies of the Big Five model in association with other aspects of personality or activity have been conducted since 2010, with earlier research mainly concerning the problem of validation and adaptation of the FFM and its personality inventories. Thus, we can clearly see the increased interest in this model and the relevance of these studies for the development of Russian psychology and psychology in general.

\section{Big Five personality traits as the factors of academic achievement}

Recently, a considerable amount of empirical research based on the Big Five model and aimed at the detection of associations between academic achievement and personality traits in students was conducted. A high predictive power of Big Five traits 
in evaluating academic achievement was discovered (Entwistle \& Entwistle, 1970; Ackerman \& Heggestad, 1997; Rosander, Bäckström, \& Stenberg, 2011; Salgado \& Táuriz, 2014). It was also discovered that conscientiousness and openness are highly associated with academic achievement in high school and university students (Salgado \& Táuriz, 2014; Poropat, 2009).

Consciousness is viewed as one of the main predictors of academic achievement in most age groups, e.g. preschool, elementary school, high school, college and university students (Noftle \& Robins, 2007) and in adult subjects undergoing additional training (Vedel, 2016; De Fruyt \& Mervielde, 1996). Consciousness shows a high predictive ability of academic achievement over a long period of long time. For example, consciousness measured on a sample of high school students is positively associated with both the grades received by the same subjects in college (Shiner, Masten, \& Robert, 2003) and the results of entrance admission exams (SAT) (Noftle \& Robins, 2007). Research demonstrates that high consciousness may also compensate for a certain degree of deficiency in intellect or cognitive ability (Murray et al., 2014). Most studies conducted on both national and international samples indicate that consciousness is the main factor (and sometimes the only one) associated with academic achievement (Murray et al., 2014; Duff, Boyle, Dunleavy, \& Ferguson, 2004).

Positive associations were found between openness and both standard academic grades and, to a lesser extent, cognitive ability (Vedel, 2016). Openness showed the most prominent associations with the SAT test results of all the Big Five traits (Noftle \& Robins, 2007). However, high levels of openness may not always correlate with academic achievement, namely for the academic subjects that require a lesser degree of creativity (to the point where openness shows negative correlations with academic achievement in such disciplines) (De Fruyt \& Mervielde, 1996; Busato Prins, Elshout, \& Hamaker, 2000).

The research indicates certain associations between neuroticism and academic achievement (Clough, Oakes, Dagnall, St Clair-Thompson, \& Mcgeown, 2016; Rosander et al., 2011). Most studies indicate that neuroticism correlates negatively with academic achievement in high school and college students (Clough et al., 2016; Rosander et al., 2011; Shiner at al., 2003).

Studies conducted on national samples, particularly on an Italian sample, revealed negative associations between extraversion and academic achievement (Hakimi, Hejazi, \& Lavasani, 2011), whereas a study conducted on an American sample revealed a positive association between the two variables (Furnham, Moutafi, \& Chamorro-Premuzic, 2005). Most studies, however, do not indicate any degree of association between extraversion and academic achievement in students (Noftle \& Robins, 2007; Kuncel, Hezlett, Ones, Crede, Vannelli, Thomas, Duehr, \& Jackson, 2005), though there are a few studies indicating negative associations (Salgado \& Táuriz, 2014; Poropat, 2009).

Some studies reveal a positive association between agreeableness and academic achievement (Furnham, Moutafi, \& Chamorro-Premuzic, 2005); however, said association is usually indirect and indicates a better adaptation ability of a person with higher levels of agreeableness, which transcends to their study habits. In general, the data on this factor is rather insignificant (Salgado \& Táuriz, 2014; Noftle \& Robins, 2007; Kuncel et al., 2005). 
Several studies of the associations between the Big Five traits and academic achievement were conducted on a Russian sample. For example, a study by E. Gavrilova revealed that conscientiousness and agreeableness may be recognised as more desirable traits in high school students, while neuroticism may be recognised as an undesirable trait. Consciousness also correlates with higher motivation, and neuroticism correlates with lower motivation in students (Gavrilova, 2013).

A study conducted by E.V. Kochergina, J. Nye \& E.A. Orel (2013) on a sample of students at the Higher School of Economics branch in Nizhny Novgorod is one of the rare Russian studies of the titular problem. The aim of the study was to investigate how the Big Five personality traits contributed to different academic achievements and to compare these findings with those of the Western studies conducted on European and American samples. The authors also analyse the similarities and differences in the psychological portraits of academically successful students in the different countries in terms of the requirements of the educational environment. The authors point out the traditional problem of establishing the success measure variable and conclude that grade point average shows a sufficiently high reliability, and it correlates significantly with other variables, such as the level of intelligence, efficiency of professional activity, professional status, etc. Therefore, in this study, as in most others, grade point average was used as a measure of academic achievement. Big Five traits were measured with a modified Big Five questionnaire consisting of 50 tasks, in each of which the respondent chooses between two given options.

A total of 176 respondents took part in the research, including 70 young men and 106 young women. All the respondents were second- and third-year Russian students of the Economics and Business Informatics Department of the Higher School of Economics branch in Nizhny Novgorod. The Unified State Examination (USE) scores were used for evaluation of academic success prior to university admission, and grade point average was used as a measure of current academic performance. Analysis revealed that neuroticism positively correlates with USE scores in math, social studies, Russian language and grade point average. Agreeableness positively correlates with USE scores in math and social studies. Openness positively correlates with USE scores in social studies. Consciousness and extraversion do not show any associations with GPA, which deviates greatly from the results of Western studies.

The research data indicate that the Big Five personality traits are significant predictors of the USE results, but they do not determine the current academic performance in university, which is confirmed by the results of both regression and correlation analysis. The authors note that the results are only partially consistent with the results of similar studies conducted in Western psychology. Differences in the educational environment of different countries and the various requirements presented by a specific university are listed among the possible causes of these inconsistencies (Kochergina, Nye, \& Orel, 2013).

In our opinion, the actual number of Big Five studies in Russia is still too small for the results to be properly compared with those of the Western studies. Thus, further research will be conducted in this direction (Krupnov, Novikova, \& Vorobyeva, 2016). 


\section{Method}

The purpose of the present study was a comparative analysis of the Big Five personality traits and their associations with academic achievement in a sample of Russian university students and as a comparison between the data obtained by the authors and the data obtained in other studies in the FFM framework, both Russian and foreign.

The main hypothesis of the study is that consciousness and openness are most significantly associated with the academic achievement of Russian university students.

A total of 207 respondents took part in the research, including 41 young men and 166 young women. All the respondents were first- and second-year Russian students of the Linguistics Department of the Peoples' Friendship University of Russia (PFUR). The age of the respondents was from 17 to 25 years; the average age was 19 years. They were advised that participation would be free and voluntary.

To measure the FFM traits, an adapted version of the NEO Five-Factor Inventory was used. The NEO (Neuroticism, Extraversion, Openness) Personality Inventory (NEO-PI), the Revised NEO Personality Inventory (NEO-PI-R), and the NEO Five-Factor Inventory (NEO-FFI) are considered to be the most commonly used versions of the Big Five personality inventories. These versions were designed by P. Costa and R. McCrae (Costa \& McCrae, 1989).

The NEO PI-R consists of 240 questions (48 items per domain) and takes about 40 minutes to complete (Costa \& McCrae, 1992). The NEO Five-Factor Inventory (NEO-FFI) is a shortened version of the inventory that uses 60 items (12 items per domain) and takes about 15 minutes to complete (Costa \& McCrae, 1992).

The Russian version of NEO-FFI, the Five-Factor Inventory (adapted by S. Biryukov and M. Bodunov) consists of 60 questions (direct and inverted) to which the subject expresses the degree of agreement from the five answer choices (from 'strongly disagree' to 'strongly agree'). The resulting values for each of the Five-Factor scales (neuroticism, extraversion, openness, consciousness and agreeableness) range from 12 to 60 points (Bodunov \& Biryukov, 1989).

It should be noted that the original NEO-FFI questionnaire and its foreign adaptations use a different assessment range compared to the Russian version. While the answer choices range from 'strongly disagree' to 'strongly agree' for all the versions, the numerical values range from 0 to 4 for the original and most of the Western versions (Costa \& McCrae, 1992) and from 1 to 5 for the Russian version (Bodunov \& Biryukov, 1989). This point should be considered when comparing the mean values of the traits in Russian and international research.

Academic achievement was assessed as the grade point average (GPA) of a subject in a certain field of study. The GPA was calculated based on the final grades received by the subject in all the specific courses that are included in a field (the raw grades range from 0 to 100). All the specific courses were divided into 5 groups, or fields, based on the national standard for the direction and curriculum (Ministry of Education and Science of the Russian Federation, 2010), which includes such units as General Education Disciplines, Special Disciplines and Foreign Language. It should be noted that the Special Disciplines field includes Psychology, Pedagogics, and Methods of Teaching Foreign Languages and Cultures, and the Foreign Language field includes both the first foreign language (English) and the second 
foreign language (selected by the student). However, given that during the final qualification tests (state exams) the subjects pass three exams, namely The Main Foreign Language (English), The Second Foreign Language and Methods of Teaching Foreign Languages and Cultures (which includes three questions, one in psychology, pedagogy and the teaching methods), we found it possible and necessary to divide these courses into separate fields.

Thus, the following fields were distinguished:

1) the English Language (as the basic course for the given sample, both in relevance and in the time spent on the study. NB: most subjects have studied English in high school, thus at the university they usually start at the intermediate level);

2) the Second Foreign Language (usually German, French, Italian, Spanish or Chinese, selected by the student);

3) Special Disciplines (Russian Language and Culture of Speech, Introduction to Linguistics, Indo-European Languages, Introduction to Special Philology, Theoretical Grammar, Theoretical Phonetics, Stylistics of the Russian Language, Comparative-Historical and Typological Linguistics, Introduction to the Theory of Intercultural Communication);

4) General Education Disciplines (History, Culturology, Sociology, Educational Anthropology, Philosophy, Political Science, Law, Economics);

5) Psychology \& Pedagogics (Psychology, Pedagogics, Methods of Teaching Foreign Languages and Cultures).

The number of students who received grades in each field differs from the total of 207 subjects for such fields as the Second Foreign Language (165 subjects) and Psychology \& Pedagogics (173 subjects) due to the fact that the sample consisted of first- and second-year students. First-year students do not study a second foreign language nor do they take any of the psychology and pedagogics courses. Eight subjects did not receive any grades in the Second Foreign Language by the time the study was conducted.

\section{Results}

\section{Big Five data}

At the first stage of the study, we examined the mean values of each of the Big Five domains (See Table 1).

The results show that consciousness (44.32) is the most prominent trait in the sample, followed closely by extraversion (42.98), openness (40.47) and agreeableness (40.73). Neuroticism is the least prominent trait in the sample (34.07). Previous research data suggests a degree of gender differences in the mean values of the traits. In the given sample, women show higher mean values for all traits (except agreeableness) compared to men.

These results match the results of various Western and Russian studies. The data suggest that women usually tend to show higher mean trait values than men and that neuroticism is usually the least prominent trait in a given sample (McCrae, Costa, 2004). Thus, the results of this study are in accordance with other studies of the Big Five model. 
Table 1. Means and standard deviations for the sample $(n=207)$, broken down by sex (raw scores)

\begin{tabular}{ccccccc}
\hline \multirow{2}{*}{ Big Five traits } & \multicolumn{2}{c}{ All subjects } & \multicolumn{2}{c}{ Men } & \multicolumn{2}{c}{ Women } \\
\cline { 2 - 7 } & Mean & SD & Mean & SD & Mean & SD \\
\hline Neuroticism & 34.07 & 7.20 & 32.20 & 6.39 & 34.54 & 7.33 \\
Extraversion & 42.98 & 7.45 & 41.44 & 9.06 & 43.36 & 6.97 \\
Openness & 40.47 & 5.44 & 39.68 & 5.44 & 40.66 & 5.44 \\
Agreeableness & 40.73 & 6.19 & 40.73 & 7.18 & 40.73 & 5.94 \\
Consciousness & 44.32 & 7.04 & 43.15 & 8.08 & 44.61 & 6.76 \\
\hline
\end{tabular}

\section{Correlation analysis}

At the second stage of the study, we examined correlations between Big Five traits and academic achievement in the sample. Spearman correlation analysis resulted in 8 significant correlations out of 25 possible correlations (See Table 2).

Table 2. Spearmen correlations between Big Five traits and academic achievement by field

\begin{tabular}{cccccc}
\hline \multirow{2}{*}{$\begin{array}{c}\text { Big Five } \\
\text { traits }\end{array}$} & $\begin{array}{c}\text { English } \\
\text { Language }\end{array}$ & $\begin{array}{c}\text { Second } \\
\text { Foreign } \\
\text { Language }\end{array}$ & $\begin{array}{c}\text { Special } \\
\text { Disciplines }\end{array}$ & $\begin{array}{c}\text { General } \\
\text { Education } \\
\text { Disciplines }\end{array}$ & $\begin{array}{c}\text { Psychology \& } \\
\text { Pedagogics }\end{array}$ \\
\cline { 2 - 6 } & $\mathbf{N = 2 0 7}$ & $\mathbf{N}=\mathbf{1 6 5}$ & $\mathbf{N}=\mathbf{2 0 6}$ & $\mathbf{N}=\mathbf{2 0 7}$ & $\mathbf{N = 1 7 3}$ \\
\hline Neuroticism & .056 & $-.158^{\star}$ & .002 & .066 & .014 \\
Extraversion & .111 & $.240^{\star *}$ & $.139^{\star}$ & .042 & .124 \\
Openness & .043 & -.026 & .125 & .104 & $.152^{\star}$ \\
Agreeableness & .087 & .096 & .073 & -.002 & .018 \\
Consciousness & .071 & $.328^{\star *}$ & $.236^{* *}$ & $.167^{\star}$ & $.195^{\star *}$ \\
\hline
\end{tabular}

Note. ${ }^{*} p<.05,{ }^{* *} p<.01$, two tailed.

As expected, most of the significant and positive relationships are between academic achievement and consciousness. Consciousness correlates positively with academic achievement in the Second Foreign Language $(r=.328, p<.01)$, Special Disciplines $(r=.236, p<.01)$, General Education Disciplines $(r=.167, p<.05)$, and Psychology \& Pedagogics $(r=.195, p<.01)$, i.e. students with higher levels of consciousness tend to score higher in these fields.

But only one positive correlation was obtained between openness and academic achievement in the Psychology \& Pedagogics $(r=.152, p<.05)$, i.e. students characterised by higher levels of openness tend to score higher in this discipline.

At the same time, extraversion correlates positively with academic achievement in the Second Foreign Language $(r=.240, p<.01)$ and Special Disciplines $(r=0.139, p<.05)$ fields, i.e. students with higher levels of extraversion tend to score higher in these fields. 
Only one inverse correlation was obtained between neuroticism and academic achievement in the Second Foreign Language $(r=-0.158, p<0.05)$, i.e. students characterised by higher levels of neuroticism tend to score lower in this discipline.

No significant correlations were obtained between agreeableness and academic achievement, which is consistent with other studies.

\section{Conclusion}

The purpose of this paper is to consider Big Five personality traits as the factors of academic achievement in Russian university students and to compare the present results with the results of previous research, both Russian and foreign. Based on an analysis of the published data, we surmise that such Big Five personality traits as consciousness and openness are more closely connected with the peculiarities of the students' academic achievement in different fields of study. Formulating the hypothesis of this study, we relied, first of all, on the results of numerous foreign studies, since there are few similar studies in Russia, and their results are rather contradictory.

Indeed, we found that consciousness has the greatest number of positive correlations with the academic achievement in Russian linguistics students. These results are consistent with the results of other Big Five studies, which consider consciousness as the prime factor used to predict academic achievement. Our research shows that consciousness is associated with higher academic achievement in different fields that imply various kinds of subjects' activity in the course of study, which corresponds with this thesis. However, academic achievement in the English language does not show any associations with consciousness, which, in our opinion, is due to the fact that the English language is viewed as the main discipline; thus, the subjects tend to work harder to score higher in this field regardless of their individual level of consciousness.

However, openness displays only one positive association with academic achievement, namely with Psychology and Pedagogics. This result is consistent with the main feature of this field namely the fact that Psychology and Pedagogics are the most unexpected for the subjects and require them to leave their comfort zone of study to try something seemingly unrelated to their educational specialisation. The association between openness and psychology as an academic discipline was found in various instances of research and requires further study.

As mentioned in the literature review, research shows that extraversion tends to display inconsistent associations with academic achievement, depending on other circumstances (Furnham, Moutafi, \& Chamorro-Premuzic, 2005; O'Connor \& Paunonen, 2007; Noftle \& Robins, 2007). Extraversion characterises the general level of a subject's activity. The Second Foreign Language and Special Disciplines require a great degree of individual activity to master the courses due to the subject's lack of experience in these fields, thus this correlation is coherent.

Neuroticism is usually associated with struggles and difficulties in various types of behaviour and activity, including education and is sometimes viewed as a predictor of lower grades (Ackerman, Chamorro-Premuzic, \& Furnham, 2011; Rosander, Bäckström, \& Stenberg, 2011; Shiner, Masten, \& Robert, 2003). Our research shows that this correlation is specific for the Second Foreign Language. Thus, we conclude 
that this association is influenced by special features of the discipline, namely the fact that a second foreign language is selected by students themselves, therefore they are in fact more responsible for their grades compared to a mandatory discipline. This situation may provoke additional stress, which may lead to lower grades for a student with higher neuroticism. The other fields are either mandatory or familiar to the subjects, which results in a lack of association between these fields and neuroticism.

We would also like to mention that the results obtained by the authors are closer to the results of similar foreign studies. As a possible cause, we see the fact that we used a grading system similar to the international variations instead of the traditional 5-point system used in Russia.

Another significant feature of the studies of the correlations between the FFM factors and academic achievement on any sample is the fact that consciousness seems to be the universal success factor. A closer analysis of these studies allows us to hypothesise that the educational (and, therefore, grading) systems are focused on correct and meticulous task completion and overall performance but does not take into account the aspects of the learning process related to creative thinking, non-typical problem solving and soft skills formation. We see that as an inherent drawback of the current international education systems, but this problem demands special attention and a different methodical approach, which may be a direction for future research.

Summing up the results of the study, it can be concluded that:

1. Consciousness as a Big Five trait shows the most prominent association with academic achievement in different fields of study, which is consistent with the aforementioned thesis and various research data of the Big Five model.

2. Academic achievement displays a greater association with Big Five traits in those fields of study that include such features as their relative novelty, difficulty or interest for students (the Second Foreign Language, Special Disciplines, and Psychology \& Pedagogics).

3. The results of the study are more consistent with those of the Western studies compared to other research conducted on the Russian sample. This might be due to both differences in the academic achievement assessment method (as most Russian universities use a traditional 4-point assessment system as opposed to the 100-point system used in Western universities) and the version of the five-factor inventory used in a specific study.

4. Prospects for research related to the study of the Russian students of other subject areas (for example, psychology, physics, economics, etc.).

\section{Limitations}

There are several limitations to our study that should be considered when conducting future research in this area. First, one limitation is the sample size and its gender composition. Because linguistics is a more popular major among females, the sample is not balanced enough in the female-to-male ratio. As the study of gender 
differences was not an objective of our research, we found it acceptable to ignore the imbalance.

Another possible limitation of this study was the measure used to collect the data. The FFM personality traits can be measured with various tools, the most popular being self-questionnaires. In our study, we used an adapted version of the most common questionnaires, NEO-FFI. This version, however, is a shortened version of NEO-PI, which could provide more extensive data, but it is not yet available in the Russian language.

A related limitation is a certain lack of prior research studies on the topic. There is a formidable amount of data available on FFM traits and their association with various aspects of social behaviour, however, only a small fraction of this data was obtained on a Russian sample, which makes it difficult to compare our results with other researchers' results and to provide a more comprehensive outlook on the cultural features.

To further this research area, future studies should consider a more balanced sample unless the gender or another imbalance can be viewed as a feature of the sample (e.g. military sample, which is male dominant). The FFM traits assessment tools are constantly being improved, which suggests the possibility of an adaptation of the NEO-PI questionnaire. We believe that data collected with the full version of the questionnaire will provide a better understanding of the problem discussed in this article. As a result, more studies will be conducted, thus providing more culture-specific data for a Russian sample to use as a baseline for future research.

\section{References}

Ackerman, P.L., Chamorro-Premuzic, T., \& Furnham, A. (2011). Trait complexes and academic achievement: Old and new ways of examining personality in educational contexts. British Journal of Educational Psychology, 81(1), 27-40. doi: 10.1348/000709910x522564

Ackerman, P.L., \& Heggestad, E.D. (1997). Intelligence, personality, and interests: Evidence for overlapping traits. Psychological Bulletin, 121, 219-245. doi: 10.1037/0033-2909.121.2.219

Azhar, M., Nadeem, S., Naz, F., Perveen, F., \& Sameen, A. (2014). Impact of parental education and socio-economic status on academic achievements of university students. European Journal of Psychological Research, 1(1), 1-9.

Bodunov, M.V., \& Biryukov, S.D. (1989). Big 5: Five-Factor Inventory. Adapted and reproduced by special permission of the Publisher, Psychological Assessment Resources from the NEO Five Factor Inventory by P. Costa, R. McCrae. Form S. Moscow: Institute of Psychology RAS.

Busato, V.V., Prins, F.J., Elshout, J.J., \& Hamaker, C. (2000). Intellectual ability, learning style, personality, achievement motivation and academic success of psychology students in higher education. Personality and Individual Differences, 29, 1057-1068. doi: 10.1016/s01918869(99)00253-6

Clough, P., Oakes, S., Dagnall, N., St Clair-Thompson, H., \& Mcgeown, S. (2016). The study of non-cognitive attributes in education. In M.S. Khine \& S. Areepattamannil (Eds.), Noncognitive skills and factors in educational attainment (pp. 315-329). Sense Publishers. doi: 10.1007/978-94-6300-591-3_14

Costa, P.T., \& McCrae, R.R. (1989). The NEO Five Factor Inventory. Odessa, FL: Psychological Assessment Resources. doi: 10.1037/t07553-000 
Costa, P.T., \& McCrae, R.R. (1992). Revised NEO Five Factor Inventory (NEO-PI-R) and the NEO Five-Factor Inventory (NEO-FFI). Professional manual. Odessa, FL: Psychological Assessment Resources.

De Fruyt, F., \& Mervielde, I. (1996). Personality and interests as predictors of educational streaming and achievement. European Journal of Personality, 10, 405-425. doi: 10.1002/ (sici)1099-0984(199612)10:5<405::aid-per255>3.0.co;2-m

Dhandabani, L., \& Sukumaran, R. (2015). Exploring the relationship between academic performances and brain dominances. Indian Journal of Science and Technology, 8(9), 889-896. doi: $10.17485 / \mathrm{ijst} / 2015 / \mathrm{v} 8 \mathrm{i} 9 / 56513$

Digman, J.M. (1997). Higher-order factors of the Big Five. Journal of Personality and Social Psychology, 73, 1246-1256. doi: 10.1037/0022-3514.73.6.1246

Duff, A., Boyle, E., Dunleavy, K., \& Ferguson, J. (2004). The relationship between personality, approach to learning and academic performance. Personality and Individual Differences, 36, 1907-1920. doi: 10.1016/j.paid.2003.08.020

Entwistle, N.J., \& Entwistle, D. (1970). The relationship between personality, study methods, and academic performance. British Journal of Educational Psychology, 40, 132-143. doi: 10.1111/j.2044-8279.1970.tb02113.x

Fazeli, S. H. (2012). The relationship between the extraversion trait and use of the English language learning strategies. Indian Journal of Science and Technology, 5(4), 2651-2657.

Funder, D. (2010). The Personality Puzzle. New York: WW Norton Company.

Furnham, A., Heaven, P. (1999). Personality and social behaviour. London: Arnold.

Furnham, A., Moutafi, J., \& Chamorro-Premuzic, T. (2005). Personality and intelligence: Gender, the Big Five, self-estimated and psychometric intelligence. International Journal of Selection Assessment, 13(1), 11-24. doi: 10.1111/j.0965-075X.2005.00296.x

Gavrilova, E.V. (2013). Vlijanie obrazovatelnoj sredy na formirovanie individualno-psihologicheskih osobennostej uchashhihsja i shkolnoj motivacii [The effect of the educational environment on the formation of individual psychological characteristics and school motivation in high school students]. Siberian Pedagogical Journal, 6, 256-259.

Goldberg, L.R. (1992). The development of markers for the Big-five factor structure. Psychological Assessment, 4(1), 26-42. doi: 10.1037/1040-3590.4.1.26

Gordeeva, T.O. (2011). Optimistic attributional style as a predictor of well-being and performance in different academic settings: A new look at the problem. In I. Brdar (Ed.), The human pursuit of well-being: A cultural approach (pp. 159-174). London, New York: Springer. doi: 10.1007/978-94-007-1375-8_14

Gordeeva, T.O. (2012). Two pathways to academic achievement: Along with well-being and away from it. Paper presented at the 6th European conference on Positive Psychology, p. 269.

Gurven, M., Von Rueden, C., Massenkoff, M., Kaplan, H., \& Lero Vie, M. (2013). How universal is the Big Five? Testing the five-factor model of personality variation among forager-farmers in the Bolivian Amazon. Journal of personality and social psychology, 104(2), 354. doi: 10.1037/a0030841

Hakimi, S., Hejazi, E., \& Lavasani, M.G. (2011). The relationships between personality traits and students' academic achievement. Procedia - Social and Behavioral Sciences, 29, 836-845. doi: 10.1016/j.sbspro.2011.11.312

Kappe, R., \& Van der Flier, H. (2012). Predicting academic success in higher education: What's more important than being smart?. European Journal of Psychology of Education, 27(4), 605-619. doi: 10.1007/s10212-011-0099-9

Katigbak, M.S., Church, A.T., Guanzon-Lapeña, M.A., Carlota, A.J., \& del Pilar, G.H. (2002). Are indigenous personality dimensions culture specific? Philippine inventories and the five- 
factor model. Journal of Personality and Social Psychology, 82(1), 89-101. doi: 10.1037/002235-14.82.1.89

Khromov, A.B. (2000). Pjatifaktornyj oprosnik lichnosti: Uchebno-metodicheskoe posobie [FiveFactor personality inventory: Study guide]. Kurgan, Russia: Kurgan State University.

Knyazev, G.G., Mitrofanova, L.G., \& Bocharov, V.A. (2010). Validizacija russkojazychnoj versii oprosnika L. Goldberga "Markery faktorov "Bolshoj Pjaterki"” [Validation of the Russian version of the "Big Five Factors Markers" inventory (developed by L. Goldberg)]. Psychological Journal, 5, 100-110.

Kochergina, E.V., Nye, J., \& Orel, E.A. (2013). Faktory "Bolshoj pjaterki” kak psihologicheskie prediktory akademicheskoj uspevaemosti studentov vuzov [The Big Five traits as predictors of academic achievements in university students]. Psikhologicheskie Issledovaniya [Psychological Studies], 27, 4-10.

Krupnov, A.I., Novikova, I.A., \& Vorobyeva, A.A. (2016). On the problem of relation between the system-functional and the five-factor models of personality traits. RUDN Journal of Psychology and Pedagogics, 2, 45-56.

Kuncel, N., Hezlett, S.A., Ones, D.S., Crede, M., Vannelli, J.R., Thomas, L.L., Duehr, E.E., \& Jackson, H.L. (2005). A meta-analysis of personality determinants of college student performance. 20th Annual Meeting of the Society of Industrial-Organizational Psychology, Los Angeles, CA.

Lodhi, P.H., Deo, S., \& Belhekar, V.M. (2002). The Five-Factor model of personality in Indian context: Measurement and correlates. In R. R. McCrae J. Allik (Eds.), The Five-Factor model of personality across cultures (pp. 227-248). New York: Kluwer Academic Publisher.

Matsumoto, D., \& Juang, L. (2008). Culture psychology. CA: Thomson Wadsworth.

McCrae, R.R. (2002). NEO-PI-R data from 36 cultures: Further intercultural comparisons. In R.R. McCrae, J. Alik. (Eds.), The Five-Factor model of personality across cultures (pp. 105125). New York: Kluwer Academic Publisher. doi: 10.1007/978-1-4615-0763-5_6

McCrae, R.R., Costa, P.T. (2004). A contemplated revision of the NEO Five-Factor Inventory. Personality and Individual Differences, 36, 587-596. doi: 10.1016/s0191-8869)03)00118-1

McCrae, R.R., \& John, O.P. (1992). An introduction to the five-factor model and its applications. Journal of Personality, 60(2), 175-215. doi: 10.1111/j.1467-6494.1992.tb00970.x

Ministry of Education and Science of the Russian Federation. (2010). National standard for the direction and curriculum.

Murray, A.L., Johnson, W., McGue, M., \& Iacono, W.G. (2014). How are conscientiousness and cognitive ability related to one another? A re-examination of the intelligence compensation hypothesis. Personality and Individual Differences, 70, 17-22. doi: 10.1016/j.paid.2014.06.014

Nizamova, E.S., Ptukha, M.V., Lobaskova, M.M. (2013). Kross-kulturnoe bliznecovoe issledovanie lichnostnyh chert "Bolshoj pjaterki" [A cross-cultural twin study of the Big Five personality traits]. Theoretical and experimental psychology, 4, 86-91.

Noftle, E.E., Robins, R.W. (2007). Personality predictors of academic outcomes: Big Five correlates of GPA and SAT scores. Journal of Personality and Social Psychology, 93, 116-130. doi: 10.1037/e514412014-495

Novikova, I.A. (2013). Big Five (The Five-Factor Model and The Five-Factor Theory). In K.D. Keith (Eds.) The encyclopedia of cross-cultural psychology (pp. 136-138). Hoboken, New Jersey: Wiley-Blackwell. doi: 10.1002/9781118339893.wbeccp054

O'Connor, M.C., \& Paunonen, S.V. (2007). Big Five personality predictors of post-secondary academic performance. Personality and Individual Differences, 43, 971-990. doi: 10.1016/j. paid.2007.03.017

Oryol, V.E., \& Senin I.G. (2004). Oprosnik NEO PI-R. Rukovodstvo [The NEO-PI-R questionnaire. Professional manual]. Yaroslavl: SPC "Psychodiagnoctics". 
Ostendorf, F. (1990). Sprache und Persoenlichkeitsstruktur: Zur Validitaet des Funf-FactorenModells der Persoenlichkeit [Language and personality structure: The validity of the fivefactor model of personality]. Regensburg, Germany: S. Roderer Verlag.

Poropat, A.E. (2009). A meta-analysis of the five-factor model of personality and academic performance. Psychological Bulletin, 135, 322-338. doi: 10.1037/a0014996

Rosander, P., Bäckström, M., \& Stenberg, G. (2011). Personality traits and general intelligence as predictors of academic performance: A structural equation modeling approach. Learning and Individual Differences, 21, 590-596. doi: 10.1016/j.lindif.2011.04.004

Salgado, J. F., \& Táuriz, G. (2012). The Five-Factor Model, forced-choice personality inventories and performance: A comprehensive meta-analysis of academic and occupational validity studies. European Journal of Work and Organizational Psychology, 23(1), 3-30. doi: $10.1080 / 1359432 x .2012 .716198$

Shiner, R.L., Masten, A.S., \& Roberts, J.M. (2003). Childhood personality foreshadows adult personality and life outcomes two decades later. Journal of Personality, 71, 1145-1170. doi: 10.1111/1467-6494.7106010

Szirmak, Z., \& De Raad, B. (1994). Taxonomy and structure of Hungarian personality traits. European Journal of Personality, 8(2), 95-117. doi: 10.1002/per.2410080203

Thalmayer, A.G., \& Saucier, G. (2014). The Questionnaire Big Six in 26 nations: Developing cross-culturally applicable Big Six, Big Five and Big Two Inventories. European Journal of Personality, 28(5), 482-496. doi: 10.1002/per.1969

Thompson, E.R. (2008). Development and validation of an international English Big Five mini-markers. Personality and Individual Differences, 45(6), 542-548. doi: 10.1016/j. paid.2008.06.013

Trull, T.J., \& Geary, D.C. (1997). Comparison of the big-five factor structure across samples of Chinese and American adults. Journal of Personality Assessment, 69(2), 324-341. doi: 10.1207/s15327752jpa6902_6

Tupes, E.C., \& Christal, R.E. (1961). Recurrent personality factors based on trait ratings. USAF ASD Tech. Rep. No. 61-97, Lackland Airforce Base, TX: U.S. Air Force. doi: 10.21236/ AD0267778

Vasileva-Stojanovska, T., Malinovski, T., Vasileva, M., Jovevski, D., \& Trajkovik, V. (2015). Impact of satisfaction, personality and learning style on educational outcomes in a blended learning environment. Learning and Individual Differences, 38, 127-135. doi: 10.1016/j.lindif.2015.01.018

Vedel, A. (2016). Big Five group differences between academic majors: A systematic review. Personality and Individual Differences, 101, 523. doi: 10.1016/j.paid.2016.05.332

Vorobyeva, A.A. (2011). The Five-Factor model: General overview. RUDN Journal of Psychology and Pedagogics, 4, 80-86.

Yushau, B., \& Omar, M.H. (2015). Mathematics performance and its relation to English language proficiency level of bilingual Arab university students. Indian Journal of Science and Technology, 8(13). doi: 10.17485/ijst/2015/v8i13/73226

Original manuscript received May 30, 2017

Revised manuscript accepted July 24, 2017

First published online November 30, 2017 